Shirath, Bachri, Sutedi, Model Listen Read Discuss (LRD) dalam Pembelajaran Dokkai

\title{
MODEL LISTEN READ DISCUSS (LRD) DALAM PEMBELAJARAN DOKKAI
}

\author{
ELIZA FAUZIA SHIRATH, Drs.Aep Saeful Bachri,M.Pd. ${ }^{1}$, Dr. Dedi Sutedi,M.A. , M.Ed . ${ }^{2}$ \\ Departemen Pendidikan Bahasa Jepang Fakultas Pendidikan Bahasa dan Sastra Universitas Pendidikan \\ Indonesia \\ elizafauzia@gmail.com
}

\begin{abstract}
Abstrak
Penelitian ini bertujuan untuk mendeskripsikan keefektifan penggunaan model Listen Read Discuss (LRD) dalam pembelajaran dokkai pada mahasiswa tingat I Departemen pendidikan bahasa Jepang. Jenis penelitian ini yaitu penelitian kuantitatif eksperimen murni dengan desain penelitian Pretest posttest control group design. Dalam penelitian ini, penulis menggunakan dua kelas yaitu kelas eksperimen yang menggunakan model Listen Read Discuss (LRD) dan kelas kontrol yang menggunakan model ThinkPair-Share (TPS). Populasi dalam penelitian ini adalah keseluruhan mahasiswa tingkat I Departemen Pendidikan Bahasa Jepang FPBS UPI. Teknik pengambilan sample dilakukan dengan Random Sampling yang diperoleh kelas $\mathrm{C}$ sebagai kelas eksperimen dan kelas B sebagai kelas kontrol. Data diperoleh dari pretest, post-test, dan angket. Hasil analisis menunjukkan nilai $t$ hitung lebih besar dibandingkan nilai $t$ tabel ( $t$ hitung $\geq t$ tabel) yaitu $5,30 \geq 2,71$ pada taraf signifikansi $5 \%$ dan $1 \%$. Dengan ini dapat disimpulkan bahwa model pembelajaran Listen Read Discuss (LRD) efektif digunakan dalam pembelajaran dokkai.
\end{abstract}

Kata Kunci : Listen Read Discuss (LRD), Dokkai, Membaca. 
JAPANEDU, Vol. 1, No. 1, April 2016

\title{
MODEL LISTEN READ DISCUSS (LRD) IN DOKKAI LEARNING
}

\author{
ELIZA FAUZIA SHIRATH, Drs.Aep Saeful Bachri,M. Pd. ${ }^{1}$, Dr. Dedi Sutedi, M. A. , M.Ed . ${ }^{2}$ \\ Departemen Pendidikan Bahasa Jepang Fakultas Pendidikan Bahasa dan Sastra Universitas Pendidikan \\ Indonesia \\ elizafauzia@gmail.com
}

\begin{abstract}
Abtract
The aims of the research are to describe the effectiveness of using Listen Read Discuss (LRD) model in dokkai learning on the first grade students of Department Japan educations FPBS UPI. This research is the kind of pure experimenting research with using Pretest posttest control group design. In this research, researcher using two class of experiments. First was experiment class that using Listen Read Discuss (LRD). Second was control class that using of Think-Pair-Share (TPS). The population of this reseach is the whole first grade students of Department Japan educations FPBS UPI. The technique of the sample is done with using Random Sampling which are obtained class C as experimenting class and class B as controlled class. The data are obtained by pretest and posttest with essay and true-fault test forms with the result value, $t$ hitung more high then $t$ tabel ( $t$ hitung $\geq t$ tabel) namely 5,30 $\geq 2,71$ on the 5\% and $1 \%$ signifikansi level. In reality, it can be concluded that Listen Read Discuss (LRD) model can be used in dokkai learning effectively.
\end{abstract}

Keyword : Listen Read Discuss (LRD), Reading Comprehensive, Reading 
Shirath, Bachri, Sutedi, Model Listen Read Discuss (LRD) dalam Pembelajaran Dokkai

読解学習Listen Read Discuss (LRD) 学習モデルによる エリザ・ファウジア

1104730

\section{要旨}

本研究の目的は 読解学習における日本語教育学科の 1 年生に対する Listen Read Discuss (LRD) 学習モデルの使用の効率を知るためである。本研究では、One group pretest- posttest design を使 用し、準実験の研究である。本研究では、2つのクラスで実験をおこない、実験クラスで Listen Read Discuss (LRD) 学習モデル方法を使用してコントロールクラスで Think-Pair-Share (TPS) 学習モデル方法を使用した。対象となったものはインドネシア教育大学言語文学 教育学部日本語教育学科の 1 年生全員である。サンプルは、Random Sampling を使用し、C クラスが実験クラスとなり、コントロールクラスにするクラスはBクラスとなった。データは エッセイテストとまるばつテストを使用した実験前テストと 実験後テストからできたものであ る。結果は水準 $5 \%$ で、 $t$ 得点 5,30 であり、 $t$ 表 2,71 である。つまり、 $t$ 得点のほうが $\mathrm{t}$ 表 くらべるともっと高い（ $t$ 得点 $\geq t$ 表）ということが分かった。そのため、読解授業における Listen Read Discuss (LRD) 学習モデルの使用は効率的だと言えよう。

キーワード : Listen Read Discuss (LRD), 読解, 読む 


\section{PENDAHULUAN}

Membaca adalah suatu proses yang dilakukan untuk mendapatkan informasi dan memperoleh pesan yang hendak disampaikan oleh penulis melalui bahasa tulisan. Dalam pembelajaran membaca pemahaman teks bahasa Jepang, siswa memerlukan proses untuk memahami apa yang dibacanya. Proses yang terjadi setiap membaca adalah sebuah proses dimana seseorang dapat menerima atau menangkap informasi-informasi yang ada dalam teks, kemudian memahaminya. Oleh karena itu, membaca diperlukan pemahaman yang baik agar siswa tidak salah dalam menyampaikan dan menemukan informasi yang terdapat di dalam teks.

Berdasarkan hal tersebut, pengajar perlu berinovasi, salah satunya dengan menggunakan model pembelajaran Listen Read Discuss. Model ini adalah model pembelajaran yang memberikan kesempatan kepada mahasiswa untuk membangun pengetahuan siswa sebelum membaca teks. LRD adalah sebuah strategi yang diambil dari teori milik Robert J. Tierney dan John E. Readence (1990 hlm:158) dalam bukunya yang berjudul Reading Strategies. (Nita, 2013, hlm: 16). Strategi ini cocok untuk pembelajaran membaca pemahaman karena strategi LRD memiliki langkah-langkah yang inovatif dan dapat membantu siswa untuk lebih memahami tujuan membaca pemahaman. Dengan ini diharapkan mahasiswa dapat memahami isi teka bacaan dengan mudah.

Sebagai perbandingan, peneliti menggunakan model Think-Pair-Share (TPS) pada kelas kontrol. Model ini telah di teliti sebelumnya oleh Frina Utami dalam skripsi yang berjudul "Evektivitas Teknik Think-Pair-Share dalam meningkatkan kemampuan membaca pemahaman mahasiswa" pada tahun 2014.

\section{METODE PENELITIAN}

Metode penelitian yang digunakan dalam penelitian ini adalah metode penelitian Eksperimental dengan desain penelitian yang digunakan adalah Pre-test post-test control group design. Sampel dalam penelitian ini adalah mahasiswa tingkat I FPBS UPI kelas C dan kelas B. Desain penelitian ini dapat digambarkan sebagai berikut:

$$
\mathrm{O}_{1} \quad \mathrm{X}_{1} \quad \mathrm{O}_{2}
$$

Keterangan :

$\mathrm{O}_{1}$ : tes awal (pre-test) kelas eksperimen

X : Perlakuan Kelompok eksperimen

$\mathrm{O}_{2}$ : tes akhir (post -tes) kelas kontrol

(Sugiyono, 2011, hlm.112) 


\section{1.) Uji analisis soal tes}

a. Tabel Perhitungan Pretest dan post-test

\begin{tabular}{|c|c|c|c|c|c|c|}
\hline No & $\mathrm{X}$ & $\mathrm{Y}$ & $\mathrm{x}$ & $\mathrm{y}$ & $\mathrm{x}^{2}$ & $\mathrm{y}^{2}$ \\
$(1)$ & $(2)$ & $(3)$ & $(4)$ & $(5)$ & $(6)$ & $(7)$ \\
\hline 1. & & & & & & \\
\hline 2. & & & & & & \\
\hline$\Sigma(8)$ & & & & & & \\
\hline $\mathrm{M}(9)$ & & & & & & \\
\hline
\end{tabular}

b. Mencari nilai rata-rata

$$
\mathrm{Mx}=\frac{\sum x_{1}}{N_{1}} \quad \mathrm{My}=\frac{\sum y_{1}}{N_{2}}
$$

c. Standar deviasi pre-test dan post-test

$$
S D x_{2}=\sqrt{\frac{\sum x 2}{N_{1}}} \quad S D y_{2}=\sqrt{\frac{\sum y^{2}}{N_{2}}}
$$

d. Menghitung standar error variabel X dan Y

$$
\mathrm{SEM} M_{x 2}=\frac{S D_{x 2}}{\sqrt{N_{1}-1}} \quad \mathrm{SEM} M_{y 2}=\frac{S D_{y 2}}{\sqrt{N_{2}-1}}
$$

e. Menghitung standar error perbedaan mean variabel $X_{1}$ dan $Y_{1}$

$$
S E M_{x 2}-S E M_{y 2}=\sqrt{S E M_{x}{ }^{2}+S E M_{y}}
$$

f. Menghitung t hitung

$$
t_{0}=\frac{M_{x}-M_{y}}{S E M_{x}-S E M_{y}}
$$

g. Memberikan interpretasi (tafsiran) terhadap nilai ' $t$ hitung'

$$
\begin{array}{ll}
\text { Merumuskan Hk } \quad \text { terdapat perbedaan yang signifikan antara } & \\
& \text { variabel } \mathrm{X} \text { dan } \mathrm{Y} \\
\text { Merumuskan Ho } \quad \text { : tidak terdapat perbedaan yang signifikan } & \\
& \text { antara variabel } \mathrm{X} \text { dan } \mathrm{Y} .
\end{array}
$$

h. Menguji kebenarannya dengan membandingkan nilai $t$ tabel 
JAPANEDU, Vol. 1, No. 1, April 2016

$$
\mathrm{db}=\left(N_{1}-N_{2}\right)-1
$$

Keterangan :

$\mathrm{db}$ : Derajat kebebasan

$\mathrm{N}$ : Jumlah sampel

(Sutedi, 2011, hlm.231-232)

\section{2.) Uji analisis soal angket}

a. Rumus untuk Menganalisis angket

$$
\mathrm{P}=\frac{f}{n} \times 100 \%
$$

Keterangan:

P : Presentasi Jawaban responden

F : Frekuensi dari setiap jawaban responden

n : Jumlah sampel

(Sudijono, 2001: hlm. 40-41)

b. Intervetasi data survey:

Tabel 3.5

Penafsiran Analisis Angket

\begin{tabular}{|c|c|}
\hline Interval Presentase & Keterangan \\
\hline $0,00 \%$ & Tidak seorangpun \\
\hline $01,00 \%-05,00 \%$ & Hampir tidak ada \\
\hline $06,00 \%-25,00 \%$ & Sebagian kecil \\
\hline $26,00 \%-49,00 \%$ & Hampir setengahnya \\
\hline $50,00 \%$ & Setengahnya \\
\hline $51,00 \%-75,00 \%$ & Lebih dari setengahnya \\
\hline $76,00 \%-95,00 \%$ & Sebagian besar \\
\hline $96,00 \%-99,00 \%$ & Hampir seluruhnya \\
\hline $100 \%$ & Seluruhnya \\
\hline
\end{tabular}

(Sudijono, 2001: hlm. 40-41) 
Shirath, Bachri, Sutedi, Model Listen Read Discuss (LRD) dalam Pembelajaran Dokkai

\section{HASIL DAN PEMBAHASAN}

berdasarkan analisis penelitian, analisis data adalah sebagai berikut :

\begin{tabular}{|l|l|l|}
\hline & Sebelum Penelitian & Setelah Penelitian \\
\hline Kelas Eksperimen & 64,5 & 88,75 \\
\hline Kelas Kontrol & 68 & 79,25 \\
\hline$t_{\text {hitung }}$ & $-0,7$ & 5.30 \\
\hline
\end{tabular}

Data penelitian menunjukkan hasil bahwa sebelum diterapkannya model pembelajaran Listen Read Discuss (LRD) dan Think-Pair-Share (TPS), kelas eksperimen memiliki hasil pretest rata-rata (mean) sebesar 64,5 dan kelas kontrol memiliki hasil pretest rata-rata (mean) sebesar 68. Setelah diterapkannya model pembelajaran Listen Read Discuss (LRD) terdapat perbedaan signifikan yang dibuktikan dengan perolehan nila rata-rata Post-test sebesar 88,75. Kelas kontrol yang menggunakan model Think-Pair-Share (TPS) Juga mengalami kenaikan nilai rata-rata menjadi 79,25. Kemudian, berdasarkan hasil analisis post-tes dengan menggunakan perhitungan statistik, maka diperoleh nilai $t_{\text {hitung }}$ sebesar 5,30 yang kemudian dibandingkan dengan nilai $t$ tabel dengan angka db 39 pada taraf signifikasi 5\% yaitu 2.02 dan taraf signifikasi $1 \%$ yaitu 2.71 maka dapat disimpulkan bahwa nilai $t$-hitung $>t$ tabel pada taraf signifikansi $5 \%$ Dan $1 \%$ Sehingga hipotesis kerja $(\mathrm{Hk})$ diterima karena terdapat perbedaan signifikan antara kelas eksperimen dan kelas kontrol.

Berdasarkan hasil angket menyatakan bahwa hampir seluruh sampel penelitian dapat memahami teks dokkai dengan diterapkannya model pembelajaran Listen Read Discuss (LRD). Model pembelajaran Listen Read Discuss (LRD) ini dapat memotivasi sampel dalam memepelajari teks dokkai dan dapat membuat teks dokkai menjadi lebih mudah untuk dipahami setelah model pembelajaran Listen Read Discuss (LRD) diterapkan. Hal ini membuktikan bahwa penerapan model pembelajaran Listen Read Discuss (LRD) menunjukkan hasil yang baik dan efektif digunakan dalam mempelajari kemampuan membaca pemahaman khususnya mempelajari teks dokkai.

Berdasarkan pada pengamatan saat proses penelitian didalam kelas, model pembelajaran Listen Read Discuss (LRD) ini dapat membuat Siswa aktif di dalam kelas juga dapat berbaur 
JAPANEDU, Vol. 1, No. 1, April 2016

dengan Siswa lain dan tidak membuat siswa individualistis. Terbukti dengan diskusi yang dilakukan selama proses pembelajaran. Kelas menjadi kondusif dengan hal-hal positif dan setiap Siswa dapat saling mengeluarkan pendapat.

\section{KESIMPULAN}

Setelah melakukan penelitian secara intensif dalam empat siklus dapat diketahui bahwa model pembelajaran Listen Read Discuss (LRD) efektif digunakan dalam mempelajari kemampuan membaca pemahaman khususnya mempelajari teks dokkai berdasarkan atas :

1. Hasil Perhitungan data sebelum dan sesudah penelitian dengan model pembelajaran Listen Read Discuss (LRD) yang menunjukkan perbedaan nilai yang cukup signifikan sehingga hipotesis kerja diterima.

2. Hasil angket yang diisi oleh respondens menunjukkan respon yang positif karena meningkatkan motivasi belajar, membuat siswa memahami teks bacaan lebih mudah, dan pembelajaran dokkai menjadi lebih menyenangkan;

\section{REFERENSI}

Sudijono. Anas 2001. Pengantar Statistik Pendidikan. Jakarta: PT Raja Grafindo.

Sugiyono. (2011). Metode Penelitian Kualitatif Kuantitatif dan R\&D. Bandung: Alfabeta.

Sutedi, Dedi. 2011. Penelitian Pendidikan Bahasa Jepang. Bandung: Humaniora. 
Shirath, Bachri, Sutedi, Model Listen Read Discuss (LRD) dalam Pembelajaran Dokkai

1.はじめに

\section{読解学習Listen Read Discuss (LRD) 学習モデルによる}

読解とは、内容を通じて伝えたいメッセージを理解し、情報を得るプロセスの 1 つの ことである。読解には、内容を通じて伝えたいメッセージを理解するのに、読者には読 解技能を身につく必要がある。読解の授業で、読む内容を理解するのに、プロセスが必 要となる。このプロセスとは、内容に書いてある情報を得、理解するプロセスである。 そのため、読解の情報を理解することで誤解が発生しないように、読解の技能は必要だ と思われる。

これに基づいて、教師が革新する必要がある。その 1 つは Listen Read Discuss （L $R D ）$ 学習モデルである。このモデルでは、教師が学生に本文の内容を完全に理解 し、アイデアを交換するためにも機会を提供することができる。この研究では、学習者 が単なる本文の内容が分かるようになる。

本研究のモデルの比較としてはコントロールクラスで Think-Pair-Share (TPS)学習モ デルを使用した。そのモデルは 2014 年の「読解力と理解を高めるため、効果 的の Think-Pair-Share の方法の使用」という Frina Utami の研究が論文の中に発 明した。

2. 研究の方法

本研究の方法は準実験の方法である。本研究のデザインは Pre-test post-test control group design である。本研究のサンプルでは、一年生 FPBS UPI C クラスおよ びＢクラスである。この研究デザインは、下語の通りである。

\begin{tabular}{|lll|}
\hline $\mathrm{O}_{1}$ & $\mathrm{X}_{1}$ & $\mathrm{O}_{2}$ \\
\hline
\end{tabular}

報道：

$\mathrm{O}_{1}=$ pretest 実験前クラスである

$X=$ 処置

$\mathrm{O}_{2}=$ posttest 実験後クラスである

(Sugiyono, 2011, hlm.112) 


\section{3. 分析の結果}

研究の分析に基ついて、データの分析は次のようである。

\begin{tabular}{|l|l|l|}
\hline & 実験の前 & 実験の後 \\
\hline 平均店実験クラス & 64,5 & 88,75 \\
\hline $\begin{array}{l}\text { 平均店コントロール } \\
\text { クラス }\end{array}$ & 68 & 79,25 \\
\hline 標準偏差実験クラス & 14,7394 & 7,8859 \\
\hline $\begin{array}{l}\text { 標準偏差コントロール } \\
\text { クラス }\end{array}$ & 15,4434 & 15,5141 \\
\hline $\mathrm{t}$ 得点 & $-0,7$ & 5.30 \\
\hline
\end{tabular}

研究のデータでは、結果の Listen Read Discuss (LRD)学習モデルを適用すると結果の Think Pair Share (TPS)学習モデルを適用する前に、実験クラスは 64.5 の予備試験結果の 平均を持ってコントロールクラスは 68 の予備試験結果の平均 を有した。Listen Read Discuss (LRD)学習モデルを適用した後に有意な差は 88.75 のインディゴ平均試験後の買 収により証明された存在である。コントロールクラスでは Think Pair Share (TPS)学習モ デルも平均值が増加した 79.25 になる。次に、統計計算を用いたテスト後の分析に基づい て、5\%の有意水準で 2.02 の数 $\mathrm{db} 39 t$ 表と比較した $t$ 得点 5.30 の得られた值は、1\%の 有意水準は 2.71、それがあると結論することができています T-カウント值が $5 \%$ と $1 \%$ の 有意水準での $t$ 表より大きい実験的なクラスとコントロールクラスの間に有意差があるた め、このように、作業仮説が許容された。

回答者によって充填されたアンケートの結果に基づき、Listen Read Discuss (LRD)学習 モデルの適用が肯定応答を取得していると結論が出た。Listen Read Discuss (LRD)学習モ デルは、学生がテキストを簡単に、より楽しく学習読解を読んで理解するために、学生 は学習意欲向上に役立つことができるためである。これは、適用 Listen Read Discuss （LRD）学習モデル が良好な結果を示し、効果的に特定のテキストが読解の研究で使用 したことを証明しています。

4. 結論

4 サイクルで集中的な研究は、Listen Read Discuss (LRD)学習モデルを効果的に基づい 読解特にテキストに読解の研究で使用されていることが分かる後は： 
Shirath, Bachri, Sutedi, Model Listen Read Discuss (LRD) dalam Pembelajaran Dokkai

1.それは学生がより簡単に、より楽しく学習読解を読んでテキストを理解するため に、学ぶためのモチベーションを向上させるため、回答者が記入アンケートの結果 が陽性反応をしめした。

2. 教室での研究プロセス中に観察は、モデル Listen Read Discuss (LRD)が、これはま た他の学生と交流し、議論の学習プロセスの間に行われるため、学生は個性行うこ とができますクラスのアクティブな学生を作ることができ、クラスが肯定的なもの とに資するなり、すべての学生が意見を利益を得ることができる。

\section{5. 参考文献}

Sudijono. Anas 2001. Pengantar Statistik Pendidikan. Jakarta: PT Raja Grafindo.

Sugiyono. (2011). Metode Penelitian Kualitatif Kuantitatif dan $R \& D$. Bandung: Alfabeta.

Sutedi, Dedi. 2011. Penelitian Pendidikan Bahasa Jepang. Bandung: Humaniora. 